\title{
National Trends in Ecstasy and Related Drug Markets around Australia
}

\author{
N. Sindicich*, J. Cassar and L. Burns \\ National Drug and Alcohol Research Centre, University of New South Wales. Sydney, Australia
}

Keywords: MDMA, Ecstasy, illicit drug, drug supply, cannabis, cocaine, methamphetamine.

\section{INTRODUCTION}

Given the recent reported decrease in availability of MDMA internationally [1] the aim of this paper is to assess the impact of that decrease in the Australian MDMA/ecstasy market. Data were obtained from a sentinel group of regular consumers of MDMA (regular ecstasy users; REU). This paper also explores to what extent this change in the ecstasy / MDMA market has impacted on other related illicit substance markets (e.g. methamphetamine, cocaine and cannabis) in relation to use, price, purity and availability.

\section{METHODS}

The Ecstasy and Related Drugs Reporting System (EDRS) is Australia's leading monitoring system in providing sensitive information on use trends, market characteristics, harms associated with use and information on new substances in the club drug scene. Data are collected annually through quantitative methods of interviewing REU ( $N=756$ in 2009) and using national indicator data sources (e.g. customs data, hospital admissions). Qualitative methods are also utilized by interviewing key experts in the law and health fields who have knowledge of (dealers/users) these substances. Methods analysis for continuous, normally distributed variables used $t$ tests and means were reported. Where continuous variables were skewed, medians were reported and the Mann-Whitney $U$ test, a non-parametric analogue of the $t$-test [2], was employed. Categorical variables were analyzed using $\chi^{2}$.

\section{RESULTS}

Ecstasy has significantly decreased in preference for REU in relation to drug of choice $52 \%$ in 2003 vs $42 \%$ in 2009 , $95 \%$ CI $0.148,0.049, \quad p<0.001$, ), concurrently, alcohol has significantly increased in preference $(3 \%$ in 2003 vs $15 \%$ in $2009,95 \%$ CI $-0.106,-0.06, p<0.05)$ over the time period 2003 and 2009. Decrease in purity and availability of ecstasy has been reported by REU. Other national data sources have also reported this decrease with the number of MDMA detections at the Australian border having decreased by over 50\%, from 116

*Address correspondence to this author at the National Drug and Alcohol Research Centre, University of New South Wales. Sydney, Australia; Tel: 02 9385 0191; E-mail: n.sindicich@unsw.edu.au in 2007-2008 to 55 in 2008-2009 [3]. The number and weight of MDMA border detections are the lowest recorded in the last decade. Interestingly, despite a lack of availability and current demand, there has been a decrease reported in median price of ecstasy tablets (between \$3-10) across all states except the Northern Territory and Tasmania in 2009. Changes in the REU ecstasy/MDMA market have occurred alongside changes in polydrug use of REU in related substance markets. There was a significant decrease in reported crystal methamphetamine use from 2008-2009, in this sample. Yet an increase in recent cannabis use $(76 \%$ in 2008 vs $82 \%$ in $2009,95 \%$ CI-0.0254, $0.1099 ; p=0.002)$ was seen nationally. Increases in cocaine seizures at the national border [3] and at a state (New South Wales) arrest use/possession level [4], have been mirrored by significant increases in cocaine use in New South Wales and Queensland. Other niche drugs (such as amyl nitrate and methadrone) in the ecstasy and related drugs (ERDs) scene have also experienced reported significant increases in use.

\section{DISCUSSION}

The results would suggest a changing trend in drug use preferences, frequency of use and practices of the 'regular ecstasy user'. There still appears to be a demand for MDMA, however, given the lack of purity and thus, decrease in positive effects of the drug, REU have anecdotally reported experimenting with other substances. The lack of MDMA availability reported by larger indicator data sources interestingly was not a prevalent finding in the 2009 EDRS study.

\section{CONCLUSIONS}

The Australian ecstasy and related drugs market is a dynamic market, emphasizing the continued need to conduct regular monitoring of use patterns and harms through systems such as the EDRS.

\section{REFERENCES}

[1] European Monitoring Centre for Drugs and Drug Addiction. Drugnet Europe 70. EMCDDA: Lisbon 2010. ISSN 0873-5379.

[2] Siegel S, Castellan NJ. Nonparametric statistics for behavioural sciences. McGraw-Hill: New York 1988.

[3] Australian Crime Commission. Australian Illicit Drug Data Report Canberra 2008-2009.

[4] Bureau of Crime Statistics and Research. NSW Recorded Crime Statistics quarterly updates. NSW Government: Lawlink Justice and Attorney General, March 2010..

Received: November 4, 2010

Revised: November 13, 2010

Accepted: November 13, 2010

(C) Scott et al.; Licensee Bentham Open.

This is an open access article licensed under the terms of the Creative Commons Attribution Non-Commercial License (http://creativecommons.org/licenses/ by-nc/3.0/) which permits unrestricted, non-commercial use, distribution and reproduction in any medium, provided the work is properly cited. 